\title{
Des pommades - ou la valeur intrinsèque de la forme galénique d'un médicament
}

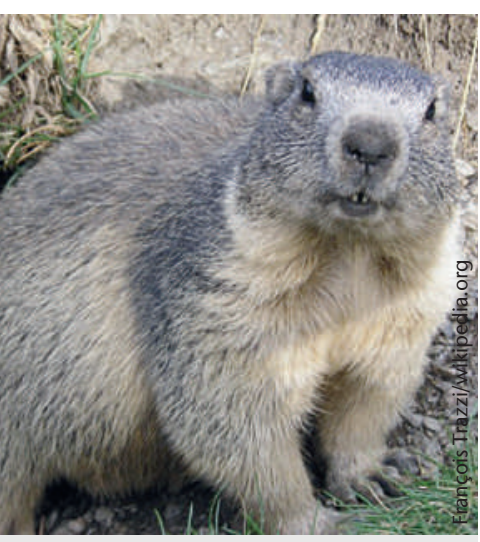

La marmotte, pas encore transformée en pommade.

\footnotetext{
PD Dr ès sc. soc. Eberhard Wolff est licencié en études culturelles, historien de la médecine et membre de la rédaction Histoire de la médecine du Bulletin des médecins suisses.
}

Comment les sorcières font-elles pour voler? Elles se servent d'un balai, évidemment. Mais pas seulement. L'histoire culturelle de l'irrationnel connait une pommade, dont les prétendues sorcières se seraient généreusement enduit les organes génitaux avant de décoller pour rejoindre leur sabbat bien mérité.

Ce n'est pas un hasard si le carburant des vols (sans doute hallucinogènes) de l'époque, quand il y en avait un, était administré en frictionnant une pommade. Dans les temps anciens, celle-ci était, avec le pansement médicamenteux, une forme galénique très populaire.

Il en était tout autrement dans les années 60 , où les pilules étaient en vogue: le personnage principal d'une série américaine, une poule mouillée classique du nom de Stanley Beamish, pouvait soudain «voler comme un aigle et vaincre tous les méchants. Son heure de gloire venait en effet à chaque fois qu'il prenait une pilule!» C'était d'ailleurs l'intro et même le titre allemand de la série. La prude télévision américaine aurait sans doute moins apprécié qu'avant de se mettre en chasse des crapules, Stanley Beamish s'enduise de pommade de superhéros, comme les sorcières.

Lorsque j'ai aidé à encadrer, il y a bien longtemps, un camp d'été pour des enfants venus de loin, la directrice utilisait une «pommade contre le mal du pays», dont elle frictionnait la poitrine des enfants tristes d'être loin de chez eux. Cela fonctionnait parfaitement - et je ne peux que le recommander en cas d'urgence. Il suffit de choisir une pommade à la consistance et à l'odeur agréables.

Du point de vue strictement médical, l'utilisation de pommades et d'onguents est pertinente lorsque la substance active doit agir localement à travers ou sur la peau. $\mathrm{Ou}$, comme dans le cas des patchs, parce que la libération transdermique systémique de principe actif est parfois mieux tolérée et plus facile à contrôler qu'avec d'autres formes galéniques ou voies d'administration.

L'intérêt de la «pommade contre le mal du pays» est ailleurs. Outre tous les effets placebo possibles, il y a la sensualité apaisante de l'application. Ne seraitce que le simple acte de frictionner avec des mains chaudes et douces. C'est sans aucun doute une forme d'administration encore plus personnelle que de fourrer dans la bouche une cuillère pleine de gouttes soigneusement comptées. L'important est le contact peau à peau, la pénétration, peut-être le parfum. Si j'étais une femme, j'ajouterais certainement ici: comme avec le maquillage!
Frictionner et enduire soulage aujourd'hui encore bien des maux, ne serait-ce que du fait de la consistance ou plutôt de la tactilité du produit. Quel amateur de Nutella pourrait le nier? L'art suisse de la pâtisserie serait-il envisageable sans les contrastes de tactilité extrêmes des mille-feuilles (tous frais) en bouche? Pour un tel feu d'artifice sensoriel, nous sommes même prêts à accepter quelques tentatives de coupe désespérées. Et quel constructeur automobile prestigieux pourrait se permettre d'ignorer la valeur ajoutée du toucher, du tactile en termes de marketing? Ce principe vaut aussi pour les pommades médicinales.

Outre leur éventuelle utilité thérapeutique, certaines ont une aura particulière propre: la pommade cicatrisante, la sombre pommade vésicante, la «pommade blanche», sans principe actif. De même qu'autrefois la pommade «grise» au mercure contre la syphilis ou «l'onguent armaire», qui contenait des ingrédients prélevés sur des cadavres et était censé guérir les plaies graves. On ne s'étonne donc guère de trouver sur Internet une étrange «pommade noire», prétendument capable de diagnostiquer le cancer et d'extraire les cellules cancéreuses de la peau. Quant au fameux «onguent de marmotte», qui contient de la graisse de marmottes fraîchement abattues à la chasse suisse, il mériterait un «Et encore...». Les ateliers pour préparer soi-même ses pommades (curatives) sont d'ores et déjà très populaires, que ce soit aux fêtes d'anniversaire enfantines ou dans les musées.

Je suis récemment passé devant le panneau d'affichage d'une église, où l'on annonçait l'onction des malades. J'avoue ne pas être expert en liturgie. Selon Wikipedia, l'onction des malades, souvent appelée extrême-onction par abus de langage, est un sacrement destiné à rendre force et courage aux personnes gravement malades ou en danger de mort, qui s'appuie entre autres sur l'épître de Jacques dans le Nouveau Testament. Elle a elle aussi des composants sensuels, puisqu'en règle générale le front et la paume des mains sont oints avec l'huile des malades (de l'huile d'olive bénite).

Chaque forme galénique et d'administration des médicaments a un caractère, une sensualité, une symbolique et une valeur propres: l'injection invasive (shot, en anglais), la pilule pratique, la pommade perceptible.

Les pommades peuvent être un bienfait pour le corps et l'esprit - même si elles ne permettent pas de s'envoler ensuite sur un balai.

Eberhard Wolff* 